\title{
Characteristics of geothermal flow in Jiangxi Province, Southeast China
}

\author{
JINHUI LIU $^{1 *}$, BAI GAO $^{1}$, FEI XIA ${ }^{1}$, XUEGANG WANG ${ }^{1}$ \\ ${ }^{1}$ East China University of Technology, Nanchang, China ; \\ (*correspondence:liujh1961@163.com,gaobai@ecit.cn, \\ fxia@ecit.cn, xgwang@ecit.cn)
}

Introduction

Jiangxi Province referred as Gan situates in the Southeast China and Southern part of low-middle reaches of Yangtze River, and is bounded by mountains on three sides. It covers an area of about 170 thousand $\mathrm{km}^{2} .118$ geothermal hot springs have been identified in Jiangxi Province, including 14 in the north, 24 in the middle and 70 in the south, and the highest temperature of geothermal water is $83{ }^{\circ} \mathrm{C}$. Geothermal (hot spring) distribution is jointly controlled by fault structure, hydrogeology, topography and lithology[1]. The geothermal flow data are obtained by the borehole geotemperature measurement and rock thermal conductivity data.

\section{Conclusions}

The results of heat flow calculation in the north, middle and south of Jiangxi Province show that: (1) The heat flow is higher in the north and south of Jiangxi, $80-200 \mathrm{mw} / \mathrm{m}^{2}$ and $116-160 \mathrm{mw} / \mathrm{m}^{2}$ respectively. The higher heat flow value is related to Jiuling uplift in the north of Jiangxi, and ZhuguangWuyi uplifts in the south, since large area of granitic plutons and the faults developed in these uplifted areas. (2) The heat flow value is relatively low in the middle of Jiangxi, generally $50-80 \mathrm{mw} / \mathrm{m}^{2}$, where is dominated by depression (belts), such as the Pingxiang-Leping depression. The faults are mainly developed at the edge of the depression, and magmatic activity is weak. (3) Xiushui and Xingzi area in the north and Ningdu area in the south are high value areas of geothermal flow, forming two typical high value areas of geothermal flow in Jiangxi Province.

[1] Qianqiang Zheng, Ming Zhong, Youping Deng, (2009) Journal of East China Institute of Technology, 32(3), 261264. 